\title{
Preserving quality of life is not incompatible with increasing overall survival in diffuse low-grade glioma patients
}

\author{
Hugues Duffau
}

Received: 1 December 2014 / Accepted: 2 December 2014 / Published online: 16 December 2014

(C) Springer-Verlag Wien 2014

In this issue of Acta Neurochirurgica, Brennum et al. [3] suggest that it could be acceptable to give patients with diffuse low-grade glioma (DLGG) the choice of more substantial surgical resection, leading to permanent neurological deficits, including with regard to motor and language functions.

Although the intention of the authors is laudable, the message here is too simplistic - and potentially dangerous - to be currently adapted to routine practice.

First of all, it has clearly been demonstrated that the extent of surgical resection has a significant impact on overall survival in DLGG patients [5, 17, 22, 23]. As a consequence, as recommended by the European guidelines, early surgery is currently the first treatment option to consider in DLGG [24]. This is the reason why some authors have achieved "supratotal" resection (i.e., extended resection with a margin beyond MR imaging-defined abnormalities) [25], especially in asymptomatic patients with incidental discovery of DLGG $[8,18]$. Thanks to the use of intraoperative functional mapping at both the cortical and subcortical level, favorable oncological and functional outcomes have been obtained [6]. Indeed, intrasurgical tasks can be adapted to the quality of life (QoL) of each patient, according to his or her job, hobbies and habits, including sensorimotor, visual, language, cognitive and even behavioral functions $[13,15]$. These results led to the recent proposal of a screening policy for DLGG [19]. However, it is worth noting that the aim of surgery is not (yet) to cure

\section{H. Duffau $(\bowtie)$}

Department of Neurosurgery, Hôpital Guide Chauliac, Montpellier University Medical Center, 80 Av Augustin Fliche,

34295 Montpellier, France

e-mail: h-duffau@chu-montpellier.fr

\section{H. Duffau}

Institute of Neuroscience of Montpellier, INSERM U1051, Plasticity of Central Nervous System, Human Stem Cells and Glial Tumors, Hôpital Saint Eloi, CHU Montpellier, 80 Av Augustin Fliche, 34091 Montpellier, France patients, but to avoid anaplastic transformation and thus induce a shift from a tumor that will become malignant if no treatment is administrated (ultimately leading to death) to a chronic disease controlled by serial treatments [12]. By applying the concept of preventive surgery, overall survival is now estimated at around 15 years since the first symptom - as recently shown in more than 1,000 DLGGs $[5,22]$.

In this setting, due to the long survival of these patients, it is crucial to preserve or even improve their quality of life. According to the European guidelines, the surgical goal is to maximally remove the tumor whenever possible while minimizing the postoperative morbidity [24]. In other words, the aim is not only to increase the extent of resection, but also to maximize the benefit-to-risk ratio of surgery, i.e., to maximize the onco-functional balance by improving both QoL and survival $[11,20]$. Indeed, it could be ethically acceptable to propose to a patient to voluntarily generate a permanent neurological deficit if it were possible to cure him or her. Nonetheless, even in cases of supratotal resection for DLGG located outside eloquent areas, whereas no malignant transformation has been observed yet, tumor relapse has already occurred [25]. Therefore, why elicit disabling sequelae by maximizing the resection for DLGG involving functional structures, knowing that the glioma will inescapably recur? Such a proposal might also let the patients believe that they could be cured by the surgery, which is currently impossible.

Rather, it would be more honest to explain to the patient and his or her family that alternative strategies can be considered in the near future. First, it is possible to reoperate on recurrent DLGG without functional worsening, with an additional reduction of the tumor volume and an increased delay before malignant transformation [21]. Indeed, subsequent surgeries may be performed with preservation of QoL, even for gliomas located within eloquent structures, thanks to mechanisms of neuroplasticity [7, 14]. Such functional reorganization has been extensively demonstrated in DLGG because of 
the slow growth of this tumor [10]. Thus, why generate a permanent deficit following a first surgery rather than preserving a normal QoL for many years and reoperating later with in fine the same oncological impact thanks to an improvement of the extent of resection during the second surgery - in a patient enjoying a normal family, social and professional life? Second, if the tumor migrates along the white matter tracts, knowing that the plastic potential is very low at the subcortical level (preventing large resection) $[10,16]$, chemotherapy can be administered. Of note, chemotherapy may preserve QoL, including cognitive functions [2], while significantly increasing survival [4]. Furthermore, chemotherapy can also induce shrinkage of the glioma, making possible a (re-)operation while preserving the functional status [1]. Such a multistage and individualized therapeutic approach enables solving the classical dilemma in DLGG (primo non nocere versus maximum survival), namely, to be more ambitious by improving both QoL and survival [12].

In summary, because it is not possible for a patient (and an expert) to imagine what it really means living with neurological disabilities, and because results from new personalized management strategies - dealing with the interactions between the course of this chronic disease, reaction brain remapping and onco-functional modulation elicited by serial treatments - have been improved $[9,12]$, it is today ethically questionable to propose generating a permanent motor or language impairment in patients with (still) incurable DLGG.

\section{Conflicts of interest None.}

\section{References}

1. Blonski M, Pallud J, Gozé C, Mandonnet E, Rigau V, Bauchet L, Fabbro M, Beauchesne P, Baron MH, Fontaine D, Peruzzi P, Darlix A, Duffau H, Taillandier L (2013) Neoadjuvant chemotherapy may optimize the extent of resection of World Health Organization grade II gliomas: a case series of 17 patients. J Neurooncol 113:267-275

2. Blonski M, Taillandier L, Herbet G, Maldonado IL, Beauchesne P, Fabbro M, Campello C, Gozé C, Rigau V, Moritz-Gasser S, Kerr C, Rudà R, Soffietti R, Bauchet L, Duffau H (2012) Combination of neoadjuvant chemotherapy followed by surgical resection as new strategy for WHO grade II gliomas: a study of cognitive status and quality of life. J Neurooncol 106:353-366

3. Brennum J, Maier CM, Almdal K, Engelmann CM, Gjerris M (2014) Primo non nocere or maximum survival in grade 2 gliomas? A medical ethical question. Acta Neurochir (Wien)

4. Buckner JC, Pugh SL, Shaw EG, Gilbert MR, Barker G, Coons S, Ricci P, Bullard D, Brown PD, Stelzer K, Brachman D, Suh JH, Schultz CJ, Bahary J-P, Fisher BJ, Kim H, Murha AD, Curran WJ, Metha MP (2014) Phase III study of radiation therapy with or without procarbazine, CCNU, and vincristine (PCV) in low grade glioma. RTOG 9802 with Alliance, ECOG and SWOG. Abstract 2000, 50th Annual ASCO Meeting

5. Capelle L, Fontaine D, Mandonnet E, Taillandier L, Golmard JL, Bauchet L, Pallud J, Peruzzi P, Baron MH, Kujas M, Guyotat J,
Guillevin R, Frenay M, Taillibert S, Colin P, Rigau V, Vandenbos F, Pinelli C, Duffau H (2013) Spontaneous and therapeutic prognostic factors in adult hemispheric World Health Organization grade II gliomas: a series of 1097 cases. J Neurosurg 118:1157-1168

6. de Witt Hamer PC, Gil Robles S, Zwinderman A, Duffau H, Berger MS (2012) Impact of intraoperative stimulation brain mapping on glioma surgery outcome: a meta-analysis. J Clin Oncol 30:25592565

7. Duffau H (2008) Brain plasticity and tumors. Adv Tech Stand Neurosurg 33:3-33

8. Duffau H (2012) Awake surgery for incidental WHO grade II gliomas involving eloquent areas. Acta Neurochir (Wien) 154:575-584

9. Duffau H (2013) Diffuse Low-Grade Gliomas in Adults Natural History, Interaction with the Brain, and New Individualized Therapeutic Strategies. Duffau H (ed). Springer London

10. Duffau H (2014) The huge plastic potential of adult brain and the role of connectomics: new insights provided by serial mappings in glioma surgery. Cortex 58:325-337

11. Duffau H, Mandonnet E (2013) The "onco-functional balance" in surgery for diffuse low-grade glioma: integrating the extent of resection with quality of life. Acta Neurochir (Wien) 55:951-957

12. Duffau H, Taillandier L (2014) New concepts in the management of diffuse low-grade gliomas: proposal of a multistage and individualized therapeutic approach. Neuro Oncol

13. Fernández Coello A, Moritz-Gasser S, Martino J, Martinoni M, Matsuda R, Duffau H (2013) Selection of intraoperative tasks for awake mapping based on relationships between tumor location and functional networks. J Neurosurg 119:1380-1394

14. Gil Robles S, Gatignol P, Lehéricy S, Duffau H (2008) Long-term brain plasticity allowing multiple-stages surgical approach for WHO grade II gliomas in eloquent areas: a combined study using longitudinal functional MRI and intraoperative electrical stimulation. J Neurosurg 109:615-624

15. Herbet G, Lafargue G, Moritz-Gasser S, Bonnetblanc F, Duffau H (2014) Interfering with the neural activity of mirror-related frontal areas impairs mentalistic inferences. Brain Struct Funct

16. Ius T, Angelini E, Thiebaut de Schotten M, Mandonnet E, Duffau H (2011) Evidence for potentials and limitations of brain plasticity using an atlas of functional resectability of WHO grade II gliomas: towards a "minimal common brain". Neuroimage 56:992-1000

17. Jakola AS, Myrmel KS, Kloster R, Torp SH, Lindal S, Unsgård G, Solheim O (2012) Comparison of a strategy favoring early surgical resection vs a strategy favoring watchful waiting in low-grade gliomas. JAMA 308:1881-1888

18. Lima G, Duffau H (2014) Is there a risk of seizures in "preventive" awake surgery for incidental diffuse low-grade gliomas? J Neurosurg

19. Mandonnet E, de Witt HP, Pallud J, Bauchet L, Whittle I, Duffau H (2014) Silent diffuse low-grade glioma: toward screening and preventive treatment? Cancer 120:1758-1762

20. Mandonnnet E, Duffau H, Bauchet L (2012) A new tool for grade II glioma studies: plotting cumulative time with quality of life versus time to malignant transformation. J Neurooncol 106:213-215

21. Martino J, Taillandier L, Moritz-Gasser S, Gatignol P, Duffau H (2009) Re-operation is a safe and effective therapeutic strategy in recurrent WHO grade II gliomas within eloquent areas. Acta Neurochir (Wien) 151:427-436

22. Pallud J, Audureau E, Blonski M, Sanai N, Bauchet L, Fontaine D, Mandonnet E, Dezamis E, Psimaras D, Guyotat J, Peruzzi P, Page P, Gal B, Párraga E, Baron MH, Vlaicu M, Guillevin R, Devaux B, Duffau H, Taillandier L, Capelle L, Huberfeld G (2014) Epileptic seizures in diffuse low-grade gliomas in adults. Brain 137:449-462

23. Smith JS, Chang EF, Lamborn KR, Chang SM, Prados MD, Cha S, Tihan T, Vandenberg S, McDermott MW, Berger MS (2008) Role of 
extent of resection in the long-term outcome of low-grade hemispheric gliomas. J Clin Oncol 26:1338-1345

24. Soffietti R, Baumert BG, Bello L, von Deimling A, Duffau H, Frénay M, Grisold W, Grant R, Graus F, Hoang-Xuan K, Klein M, Melin B, Rees J, Siegal T, Smits A, Stupp R, Wick W (2010) Guidelines on management of low-grade gliomas: report of an EFNS-EANO Task Force. Eur J Neurol 17:1124-1133

25. Yordanova YN, Moritz-Gasser S, Duffau H (2011) Awake surgery for WHO Grade II gliomas within "noneloquent" areas in the left dominant hemisphere: toward a "supratotal" resection: clinical article. J Neurosurg 15:232-239 